\title{
DEBAT
}

\section{Debat: Op weg naar een wereldwijd parlement van burgemeesters?}

\author{
Wereldwijd Burgemeestersparlement: utopie of utiliteit?
}

\author{
Bas Denters
}

\section{Inleiding}

Dit is het eerste nummer van Bestuurswetenschappen, nieuwe stijl. Het tijdschrift is met ingang van deze jaargang - zoals het nieuwe colofon ook aangeeft volledig gewijd aan het lokaal bestuur. Het blad richt zich op de lokale aanpak van maatschappelijke vraagstukken en de manier waarop deze gestalte krijgt in de wisselwerking tussen burgers, maatschappelijke organisaties, bedrijven en diverse overheden. De term lokaal bestuur hanteren we daarbij in de ruime zin van het woord. Het gaat zowel om het territoriaal (gemeenten en provincies) als het functioneel gedecentraliseerd bestuur (waterschappen, openbare lichamen en zbo's), bestuurlijke hulpstructuren (gemeenschappelijke regelingen en dergelijke) en om de wereld van lokaal actieve 'maatschappelijke ondernemingen' en maatschappelijke initiatieven (voorheen particulier initiatief). Ook het functioneren van netwerken van dit soort organisaties is vanuit het perspectief van het blad relevant. Uiteraard zullen in Bestuurswetenschappen ook vraagstukken betreffende de interbestuurlijke verhoudingen en de inrichting, omgangsvormen en bestuurlijke processen in het binnenlands bestuur aan de orde kunnen komen.

In dit eerste nummer 'nieuwe stijl' besteden we aandacht aan het spraakmakende boek If Mayors Ruled the World van de Amerikaanse politiek theoreticus Benjamin Barber uit 2013. Het boek, dat in maart 2014 ook in een Nederlandse vertaling verscheen, heeft sinds het verschijnen veel publiciteit gekregen, zowel in de geschreven pers (in onder meer de Volkskrant, Trouw, NRC Handelsblad, Financieel Dagblad) als op de televisie (Tegenlicht, 28-09-2014). Bovendien bezocht Barber in 2014 liefst drie maal ons land om met allerlei belangstellenden van gedachten te wisselen over dit boek. Vooral burgemeesters en andere lokale bestuurders stelden belang in Barbers boodschap. Zo sprak Barber op 17 juni 2014 bijvoorbeeld tijdens het plenaire deel van het Jaarcongres van de Vereniging van Nederlandse Gemeenten in de Drechtsteden.

In dit nummer staan we stil bij een van de meest controversiële onderwerpen die Barber in zijn boek behandelt, namelijk zijn voorstel om een Wereldwijd Parlement van Burgemeesters in te stellen. Voordat Barber in hoofdstuk 12 van zijn boek dit voorstel doet, is hij eerst ingegaan op het tekortschieten van de nationale 
staat en zijn democratische instituties bij de oplossing van de grote maatschappelijke uitdagingen - op het terrein van bijvoorbeeld het duurzaamheid- en klimaatbeleid, migratie en integratie en terrorisme en veiligheid - waarvoor onze planeet zich in de 21e eeuw ziet gesteld. Barber is vervolgens veel positiever over het probleemoplossend vermogen van het stedelijk bestuur. Hij betoogt dat pragmatische lokale bestuurders - zonder ideologische preoccupaties en gebruikmakend van internationale stedennetwerken - bij de aanpak van dergelijke vraagstukken vaak meer weten te bereiken dan nationale politici. Daarom stelt hij zich op het standpunt dat onze tijd een 'Age of Cities' zal zijn waarin samenwerkende steden bij de oplossing van mondiale vraagstukken in toenemende mate een alternatief zullen vormen voor de nationale staten en bestaande internationale organisaties als de Verenigde Naties. Als sluitstuk van het zich ontwikkelende stelsel van internationale steden netwerken stelt Barber voor om over te gaan tot oprichting van een Wereldwijd Parlement van Burgemeesters (WPB).

De eerste bijdrage aan dit themanummer is van de hand van Benjamin Barber zelf. In zijn artikel licht Barber zijn voorstel voor dit Wereldwijde Parlement van Burgemeesters toe en gaat hij in op de manier hoe - gebruikmakend van nieuwe informatie- en communicatietechnologie (ICT) dit voorstel werkelijk vorm gegeven kan worden. Bovendien schetst Barber ook de vorderingen die sinds het verschijnen van zijn boek in 2013 zijn gemaakt met de oprichting van deze institutie.

Een tweede bijdrage is van de hand van de de Belgische emeritus hoogleraar Sociale en Culturele Geografie aan de Vrije Universiteit te Brussel (VUB) Eric Corijn. Hij was daar ook directeur van het VUB-studiecentrum voor stedelijk onderzoek Cosmopolis, City, Culture and Society. Corijn ondersteunt Barbers pleidooi voor een mondiaal parlement van burgemeesters. Daarbij gaat hij niet alleen in op de redenen waarom in zijn visie op dit moment behoefte bestaat aan een dergelijk initiatief, maar hij geeft ook aan welke thema's hoog op de agenda van dit parlement dienen te staan. Ten slotte adviseert hij bij de ontwikkeling van het initiatief pragmatisch te werk te gaan.

De derde bijdrage wordt verzorgd door Michiel Herweijer. Hij is als buitengewoon hoogleraar Bestuurskunde verbonden aan de Radboud Universiteit Nijmegen en houdt zich onder meer bezig met onderzoek naar gemeentelijke herindelingen en intergemeentelijke samenwerking. In zijn bijdrage formuleert hij zes punten van kritiek op Barbers pleidooi voor een burgemeestersparlement.

In een slotbeschouwing ga ik tegen de achtergrond van de drie andere bijdragen in op de vraag die ook in de titel van dit themanummer centraal staat: in hoeverre is het voorstel van Barber utopisch? Daarbij komen zowel de wenselijkheid (bieden de voorstellen een overtuigend en aantrekkelijk toekomstperspectief) als de haalbaarheid van de voorstellen aan de orde. 